\title{
Chapter 6 \\ Reunion with Others: Foundations of the Presentational Self in Daily Lives
}

In this chapter, I further explore the fundamental dynamics that bring about the emergence of children's presentational selves. These were discussed in the foregoing chapters on the basis of children's meaning construction in two types of activity: mother-child conversations and children's writing of personal stories. These all happened in natural settings, and in relation to the methods of data collection, I discussed the methodological and epistemological differences between many studies in developmental psychology concerning children's selves (e.g., self-understanding, self-esteem) and the framework of the presentational self. The self is now what emerges to be observed in the meaning construction required in the ordinary lives of children, not a reflection of stable entities that children internally maintain.

To pursue the nature of the framework under discussion, we must elaborate the understanding of how children's presentational selves distinctly emerge in their lives. For example, rich meaning construction with a detailed figure of a child's self occurs only rarely and whimsically in recurring conversation. So why do children only occasionally engage in the meaning construction that makes their selves more differentiated? This is also a question that concerns the relationship between the episodic and the general natures of our minds. Although our minds work within the episodic contexts we pass through every day, how can we understand this in relation to the general aspects of our minds that are constantly at work? ${ }^{1}$

To answer this question, I first focus on the potential of mundane environments and the role of reunion that exists in children's (and more generally, our own) lives. Our recurring meetings with other people or objects in our daily lives can be a starting point for meaning construction. What becomes crucial in this movement are several dialectic tensions that exist at the foundation of these reunions. The dialectic tensions are "visible $<>$ invisible" and "same $<>$ non-same", and they promote meaning construction concerning children in the past, present, and future.

\footnotetext{
${ }^{1}$ The relationship between the episodic and the general here is comparable with the distinction between episodic memory and semantic memory (Tulving 1972). They are considered different systems, but they overlap in some aspects and construct the system as a whole.
} 


\section{Why Do Children (and We) Occasionally Go Into and Develop Meaning Construction?}

Although it sounds very ordinary for us, since we do not carefully examine our conversations every day, episodes of conversation that clarify children's presentational selves, as do the excerpts in Chap. 3, do not appear frequently in natural settings. For example, as shown in Chap. 3, over $34 \mathrm{~h}$ of recorded conversation between Mina and her mother included only 50 episodes that referred to Mina and her friends at hoikuen. Children's writings as discussed in Chap. 5 were also non-stable: that is, uncovering consistent ontogenetic changes in their meaning construction from the stories written in a single academic year proves difficult. They would often write very simple stories in the days after producing a story including a variety of meaning constructions (for example, their focus on the details of interaction and their own internal dialogue).

The question of this instability of repeated meaning construction has not been discussed seriously in studies of psychology that consider variations or fluctuations of our everyday conduct as measurement errors to be ignored. In the studies of developmental psychology concerning mother-child conversation, researchers asked children and their parents in specially prepared settings to talk about past experiences, rather than waiting for natural occurrence of conversation (Chap. 4). However, if we rely on the framework of Fig. 2.1, we must consider the entirety of the constructed interactions in which children are involved, and elaborate the process. In other words, we must understand not only the process of our dialogue but also what leads it.

This does not mean that existing studies failed to consider the way children participate in the work of meaning construction. In particular, studies involving motherchild conversations have explained that parents who take part in conversations play an important role in this process. As we saw when analyzing the excerpts, an episode of conversation often starts with the mother's (or another adult's) questioning about what a child has experienced. Many studies emphasized the parents' role in conversation, focusing on individual differences of their elaboration: i.e., frequent use of open questions and providing details of the children's experiences during the conversation (Fivush, Haden, \& Reese, 2006). In addition, as briefly introduced in Chap. 3, the importance of facilitating the conversation is also recognized by the mothers themselves (e.g., for gathering information concerning their children's behaviors) (Komatsu, 2000, 2013). However, these discussions do not fully explain why mothers like to ask questions, as they lack the description of fundamental dynamics that bring about the conversation.

For children's writings about their experiences, many schoolteachers kept records of how they had read and interpreted each child's stories. Among these records, some were considered fine educational practices and became well known. However, for this reason, they do not necessarily explain the whimsical nature of the writings. Teachers described the struggles in life or the beauty of innocence observed in children's stories through their educational efforts. However, these particular stories were essentially picked up from among vast numbers of stories as fine and moving 
examples, and as such, they are not necessarily applicable to the daily practices described in Chap. 5. Further, as already discussed in Chap. 5, studies of developmental psychology and educational psychology failed to develop detailed analyses of these writings in relation to children's development in society.

Thus, to understand these processes further, we need to move from a psychological concept of style or motivation for conversation and the background of children's writings that includes personal problems (e.g., economic difficulties mentioned in tsuzurikata before WWII) to the more abstract, general dynamics in our lives that promote children's meaning construction. In this inquiry, I examine our lives at two levels of abstraction-one in the structure observable within the practices of our lives, and another at a more abstract level of the dialectic dynamics. They work in close relationship with each other to promote meaning construction that leads to the emergence of the presentational self.

\section{The Potential of Mundane Settings for Meaning Construction}

For this inquiry, first we must understand the potential of children's mundane environments to clarify who they are. In the school setting, children encounter multiple meaning systems they use to position themselves. There are, for example, children's shoe shelves and desks standardized in both size and design (Fig. 6.1): objects that
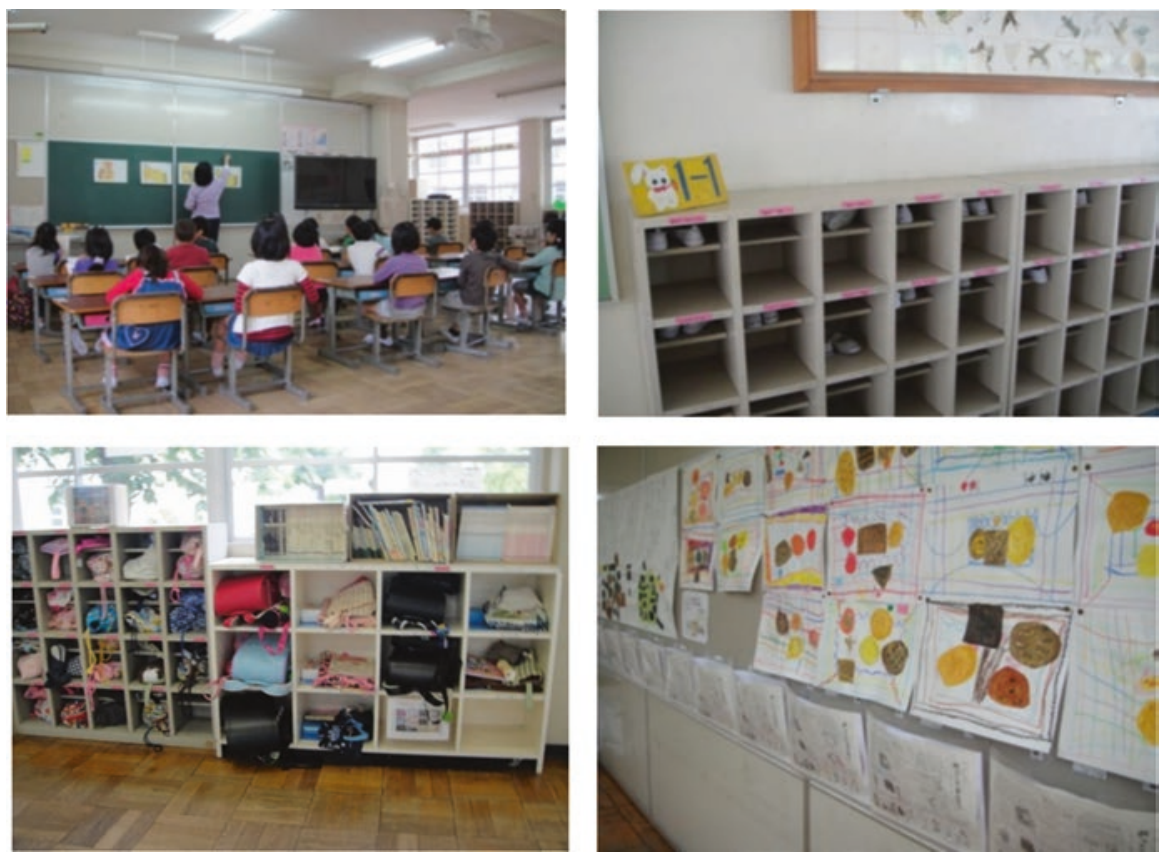

Fig. 6.1 A classroom in a Japanese elementary school (first grade) (Komatsu, 2015, p. 288, Figure 17.1) Note: The pictures were taken and used with permission 
don't exist in their home. These are almost entirely fixed, non-changing environments and serve as a stable order in which children can position themselves. Their institutionalized meanings are clear (e.g., "I have my shoe box in the second tier, because the nameplates of the boxes are in alphabetical order and my name begins with T"). Thus, the familiarity of children's mundane environments serves to stabilize who they are at school-in other words, a child's understanding that "My shoe box is there" constructs his or her feeling that "I was there," and clarifies his or her existence at school as a whole.

Of course, the stability of these environments does not mean they keep children exactly the same every day. They constantly exert influence on children to commence meaning construction in a variety of ways, because such environments always entail uncertainty and further possibility of meaning construction. For example, a shoebox in school that bears a child's name can facilitate a child's constructing of meaning from it quite different from the institutional one (e.g., "I like the girl whose shoe box was next to mine"). At first glance, mundane environments appear totally different from questions in interviews asking participants to reflect, or works of modern art that shake our understanding of the world and ourselves, but they still carry potential for meaning construction and clarification of ourselves reacting to them.

In these environments, naturally, an abrupt change of our relationship with our ordinary environment causes further meaning construction. In discussing signmediated processes of self-reflection, Gillespie (2007) listed four types of reason: "ruptures (problems with the subject-object relation), social feedback (where the other acts as a mirror), social conflict (in the struggle for recognition), and internal dialogues (through internalizing the perspective of the other on self)" (p. 689). Although Gillespie's discussion is aiming at deeper self-reflection, as illustrated by stories of English travelers to India, these dynamics also appear in our encounters with objects or others in daily settings. For example, a rupture presupposes a harmonious relationship with others or objects before it happens, and it occurs at some point of time when such a relationship changes. From this basic understanding, our loss of a favorite pencil or experiencing the sudden breakdown of a laptop full of precious data is a kind of rupture in our mundane environment, and can lead to our elaborated meaning construction concerning these events.

\section{Reunions in Our Lives Show a Two-Sided Nature: An Inevitable Consequence of Modern Life and a Commodity to Be Consumed}

In our daily lives, what exists at the base of the meaning construction described in the previous section are our repeated encounters, or reunions, with our objective and interpersonal environments, and what bring about equilibration and dis-equilibration are also often contained in these reunions. Such reunions are ubiquitous in our lives. Institutionalized settings such as school or workplace and intimate relationships in 


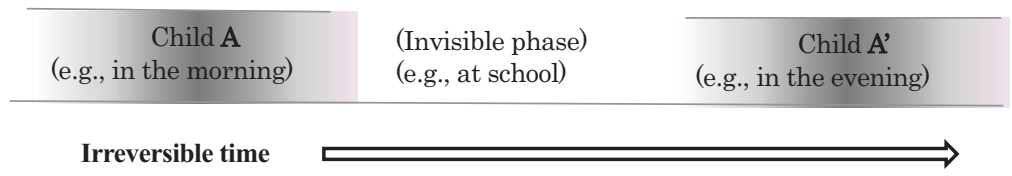

Fig. 6.2 Model of a child's daily movement and his or her invisibility from a parent's perspective

our home show qualitative differences in what we expect will happen and what we are expected to do, and we transfer between these circumstances regularly. As discussed in Chap. 3, this boundary crossing experience in life makes the child's relational position unstable, and it brings about reunions as daily events.

If we look at this process focusing on the visibility of children, these movements produce a phase of their lives that is invisible to their parents, which constructs potential differences between who the child is in the morning before school and who he or she is after returning home (Fig. 6.2). Conversely, children's lives in their homes are invisible for teachers at school. In these transitions, meaning construction in conversation (Chap. 3) occurs upon the reunion of children with their mothers, and children's writings about their experiences (Chap. 5) can be considered as something prepared for children's reunions with their teachers or classmates.

Generally speaking, these reunions occur when we divide our lives (e.g., by going to school every day), as moments that characterize the structure of our lives. If we extend the length of separation and frequency of reunions, they can be seen to exist in various moments in life-e.g., family gatherings in holiday seasons, conference meetings, homecoming days - and most of them are closely related to the dissection of our lives in time and space. In addition to reunions after physical separation, we also experience pseudo-reunions across time using a variety of devices. For example, photographs or videos enable us to meet others in the past, even including ourselves in the past.

At the same time, this word "re-union" connotes that whoever (or whatever) meets there should return to a state of unity, and the concept of reunion here introduces the presupposition that opposes the division. In relation to this presupposition, affective value is attached to reunions, especially when unexpected or after very long separations. However, reunions are not necessarily the result of adverse separations. Considering the examples of a class reunion or parents eagerly taking photos of their children for their (pseudo-)reunion in the future, we actively arrange reunions that are not necessarily required for our lives.

Thus, reunion is not only the inevitable result of the division of our lives but also what we consume in society as a kind of commodity. This suggests that reunion exists in our lives with contrasting characteristics. In one aspect, it is an unavoidable by-product of the society we live in, wherein unity must be achieved despite divisions. On the other hand, it is what we expressly produce for our pleasure or affective experiences by identifying the divisions for which we do not care if there is no reunion. 
Referring to the importance of mundane environments and the ubiquity of reunion, I briefly described the backgrounds of children's meaning construction that are observable in the structure of their lives. However, understanding how they work to bring about children's commitments to semiotic activity needs further discussion of its underlying dynamics.

\section{The Foundation of Reunion: Two Dialectic Tensions}

To understand the function of reunion in our lives, here I assume two types of dialectic tension - same $<>$ non-same and visible $<>$ invisible — that play an important role in this process. They are closely related to, or rather inseparable from, reunion and meaning construction. In the analyses of conversation and writings, I already discussed how the dialectic dynamics of our language lead to meaning construction (Chaps. 3 and 5). However, in contrast with the dialectic dynamics that are traceable in the progression of conversation or in writings, here I consider dialectics at a more abstract level not observable in the concrete traces of meaning construction.

Firstly, reunion involves the phases of visible and invisible as its foundation. In the flow of time, the reunion is the point at which invisible switches to visible, or at the boundary of two qualitatively different times, and this indicates reunion and (in) visibility are co-definitive. Valsiner (2007) discussed this type of triplet relationship using C. S. Peirce's discussion. As we see in Fig. 6.3, Peirce emphasized the unique character of the present that is very close to, or dependent on, both past and future but brought about in between them.

In his discussion concerning the triplet of past, present, and future, Valsiner described the function of signs in the present thus: "It is through the construction of signs-iconic, indexical, and symbolic - that the perceiving/acting organism faces the future. Cultural psychology assumes the act of construction of novelty by the organism, based on the resources of the given setting and the experiences of the past transported to the present (...)" (p. 130). This suggests the importance of the reunion as a unique point at which semiotic activities are promoted in relation to the invisible past and to cope with the future, from the perspective of parents. Mothers' eagerness to talk about their children's experiences may stem from this unique property of reunion.

Secondly, this tension concerning visibility brings about the dialectic tension of same $<>$ non-same that also establishes the occurrence of reunion. Reunion is realized when we create the illusion of the sameness of whom or what we encounter, even if only a fragment of it. For example, it cannot be a reunion if I see someone on a bus whom I actually met 10 days ago but failed to recognize his or her sameness and thus the dialogue never occurs. However, a dramatic reunion can take place when we meet a classmate from elementary school after 40 years of no contact, though there remains only one aspect (e.g., his or her name) capable of proving the identity of this person who was just a child in the class. This easily causes a dialogical process to clarify who we were during the separation with the elaboration 


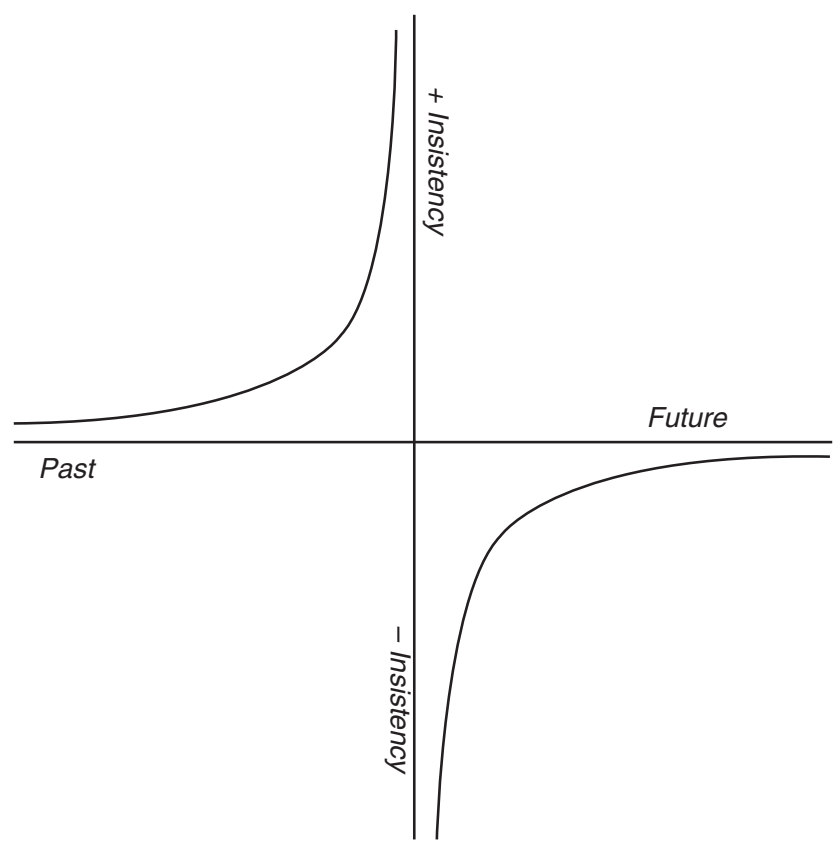

Fig. 6.3 Peirce's model of the relationship between the past, present, and future (Peirce 1892, p. 550)

or explication of the sameness and non-sameness of ourselves. In other words, the semiotic construction of sameness is not confirmation of the perfect identity, but rather the unification of the invisible past and the visible present.

Thus, reunion involves two types of dialectic tensions, and all of these things are co-definitive with each other. In the flow of time, they are always on the move and the exploration of sameness leads to further meaning construction. The affective value of reunion and our deliberate arrangement of it are also related to these two tensions. For example, in reunions after very long separation, the construction of a minor sameness out of similarity exists in stark contrast with extreme non-sameness (a strong tension of same $<>$ non-same). This can make us experience strong affects as its derivatives, facilitating the construction of further sameness with each other amid the deluge of non-sameness.

\section{Reunion, Prediction, and Psychology}

Many theories of psychology also place the reunion and our reaction to it at the core of their theoretical frameworks. Looking at the theories concerning human development, the set of separation and reunion is at the core of the Strange Situation procedure (Ainsworth, Blehar, Waters, \& Wall, 1978), which is widely used for 
clarifying the styles of attachment. Here, the way in which reunion is achieved serves as one of several criteria for understanding the quality of the relationship between infants and attachment figures. Earlier in the history of psychology, the framework of Pavlovian conditioning also emphasized the role of repeated encounters with neutral stimulus paired with unconditional stimulus. Although the reunion here is not necessarily a semiotic construction, a conditional response to a conditional stimulus appears when we feel we've encountered the similar stimulus again.

An interdependence of the reunion and the two types of dialectic tension discussed above also exists in these procedures within psychological studies. In the separation and reunion of the Strange Situation procedure, we observe how the separation from (i.e., invisibility of) the attachment figure affects a child's conduct and how the relationship recovers to the same as before the separation when the attachment figure is visible (available). Pavlovian conditioning is based on the production of a reaction based on the recognized sameness of a conditional stimulus, if the original, unconditional stimulus is non-present. Thus, from the perspective I introduced in the foregoing section, these procedures make use of the two dialectic tensions to clarify the functioning of our minds.

If we take an extended view, the importance of reunion in psychological discussions is not limited to these procedures. Studies of psychology in many areas have a foundation in reunion because they consider the prediction of behavior one of their crucial aims. Prediction of behavior works in our encounters with others or environments, and is closely related to the construction of sameness concerning self and others in our relationships. For this need, concepts of psychology (e.g., personality traits) bring us conceivable understanding of self and others (e.g., Today, he complained about his work as always.). Thus, many people feel a sense of relief when constructing the quasi-sameness of a person, including themselves, although in reality these psychological concepts have little ability to predict our behavior. Actually, using personality concepts for understanding is somewhat tautological: we "understand" the reason for a person's behavior that he or she has a tendency to behave in that way. However, this tautological understanding of one's personality constructs a plausible pair of expectation and realization, preparing the expectation to be realized, and we feel comfortable with that prediction ensuring the constructed sameness of self and others.

\section{The Role of Dialogical Meaning Construction in Reunion}

The discussion above shows that constructing the phantasmal sameness of self and others is inevitable in reunion, and as we saw in foregoing chapters, telling and writing personal stories are activities that work in the semiotic regulation of this same $<>$ non-same tension. As is clear from the stories previously analyzed, this is not the construction of the precise sameness of others or ourselves, because one function of our personal stories is explaining what happened in the time that was invisible to our partner in the interaction. Stories clarify the non-sameness of us in 
the present and in the past. In other words, discovery of the sameness enables the reunion, but it always involves the non-sameness.

Although this may explain the role of our meaning construction in reunion, it still does not describe the occasional nature of the occurrence of such semiotic activities. If storytelling is a powerful way of regulating this same $<>$ non-same tension of ours, why does it appear in non-regulated or non-predictable ways? In these complexities, we must understand that our actions do not follow a simple schema of causation and result, but are instead what occurs amid dialectic tensions that are always on the move, though this may sound like an abandonment of psychology's basic premise. Children's storytelling works within the tension of same $<>$ nonsame functions, in combination with other factors also related to this tension. In the next section, I attempt a somewhat bold leap to compare this framework-that is, our needs of regulating same $<>$ non-same tension in reunions-with what we do when listening to music, in order to offer suggestions concerning the occurrence of meaning construction.

\section{Reunion in Music: An Analogical Discussion on the Regulation of Reunion}

Whether classical or pop, most musical compositions based on western music employ the variation of a "motif" or "theme" that appears repeatedly throughout the piece. Not only the tunes on the Billboard hit chart but also the masterpieces by J. S. Bach or L. van Beethoven rely on the reunion of the listeners and (variations of) a motif introduced in the beginning, or in the middle, of the flow of continuing movement of sounds. In other words, it is in our repeated encounters with this "almost the same but also non-same" melody that we experience our affective reaction to the entirety of a music piece-its meaning to us.

These reunions in the music we enjoy are commonly based on the order that dominates them. A theme in a musical piece also repeats in ways that fulfill our expectations, though many composers of music have challenged this order, as I discuss later. We are excited and satisfied when a favorite theme, whether romantic or brave, appears again at the climax, and we consider it strange if an intermezzo halts suddenly and the music switches to the climax directly. It is not only through such changes of mood but also in the proceeding of harmony and dynamics that we anticipate the arrival of a main theme. Although a piece may contain many transformations of tempo and tonality, what we listen to is basically dominated by organized tempo and standards dictating how one chord leads another, as textbooks of musical grammar tell us.

The system that dominates the reunion is also what makes us understand the reunion. In the history of music, especially in the nineteenth century, composers pursued novelty in their works by introducing harmonies that made novel impressions on listeners. Through these attempts, the format of music as dependent on major and minor keys was well elaborated-at the same time, the limitations of 
this system were already understood by composers (Griffiths, 2006). Despite this historical fact, most musical works circulating in contemporary societies rely heavily on this system with major or minor keys in their makeups. Even the latest hits, the music that people eagerly enjoy and feel is understandable, are just arrangements of the classical, standardized system that has been in use at least during the twentieth century.

The fact that many experimental music pieces are appreciated only by a few enthusiasts and that many people believe these pieces "very hard to understand" implies that the system described above is essential for many people in the repeated reunion with a melody. Historically, certain composers in the twentieth century-P. Hindemith and D. Shostakovich, for example - who experimented with new styles of music were oppressed by Hitler or Stalin (Griffiths, 2006). This illustrates how music in excess of expectations makes people confused and sometimes irritated. Thus, our meaningmaking in music achieved through repeated encounters (reunions) with a short motif is comfortable when this is some arrangement of a ready-made, fundamental structure. This basic idea shows some affinity to the role of psychological concepts in our understanding of self and others in reunion as discussed in the previous sections, in that both of these serve to fulfill our expectations.

\section{Suggestions from the Trials of Music History: A Focus on the Openness of Reality}

Viewed from a commercial perspective, the order of music that controls the reunion and keeps it comfortable for us has demonstrated great success. However, from the beginning of the twentieth century, many composers aware of the limitations of the traditional system of music attempted to explore further possibilities. Atonality was an early example of this challenge, which rejected the order adopted for composing in the nineteenth century. John Cage (1912-1992), who once was a student of A. Schoenberg, was a composer who extended his attempts beyond the existing order of music, denying the authority of composers or players in varied ways. Extending from the discussion above, in which I sought to understand the psychological dynamics of everyday life as an analogue of music, here I inquire into a new possibility of psychological study referring to his method of composition.

Griffiths (1981) used the concepts of silence, contingency, and natural sounds to characterize Cage's explorations. First played in 1952, his well-known work $\left\langle 4^{\prime} 33^{\prime \prime}\right\rangle$, in which a player or players play tacet (in silence) on stage, emphasizes not only the possibilities of silence as music but the existence of a variety of sounds in the environment or in our physical sensations (e.g., heartbeats) that still exist when there is no performance of traditional music (Griffiths, 1981). His eagerness to use many types of sound other than those of typical musical instruments is clear in his early compositions featuring a prepared piano that produced sounds from objects placed between the piano's strings. He also used atmospheric sounds, considered superfluous noise according to the accepted principles of music or concerts. His exploration 
to transcend the constraints of traditional music was not limited to the sounds he used, but extended to the way a composition is achieved by introducing coincidences in the composition process. Griffiths (1981) suggested that Cage's emphasis on coincidences and the unknown derived not from his personal preferences, but from his deep respect for our ordinary lives dominated by lack of control.

Cage's willingness to introduce contingency against the existing order that gives us the sense of predictability and the sense of sameness in reunion must be justified with our understanding of human action in transcending the restrictions of existing presuppositions. Here contingency can be understood as openness to what may happen in reunion. If I apply this idea to the mother-child conversation, reunion is open to a variety of possibilities concerning the sameness of the child. To illustrate this relationship, here I modify Fig. 6.2 as Fig. 6.4. In a reunion of a child with his or her family, there are demands for constructing the sameness of the child and family relationships as before: not only with family members but in the child himself or herself. This sameness exists in a dialectic tension with the non-sameness that becomes evident in the flow of time or through their experiences. This tension prevails in music also - that is, we anticipate the re-appearance of the same motif in an arrangement that leads to the finale of a piece. However, the tension of same $<>$ non-same in real interaction is not controlled in this way but is instead open to a variety of possibilities, as Cage attempted to show us in his composition emphasizing the contingency and diversity of the sounds we hear in silence.

Here I consider the interaction and meaning construction in the mother-child conversation discussed in Chaps. 1 and 3 as one actual way to construct this sameness and non-sameness.

\section{(From Excerpt 1.2)}

1 Mo: What is Saito Taku [Mina's friend, boy] (yes) going to play in the theater performance? (1 s).

2 Mi: A bat. (2 s) And Mina [I play] a rabbit.

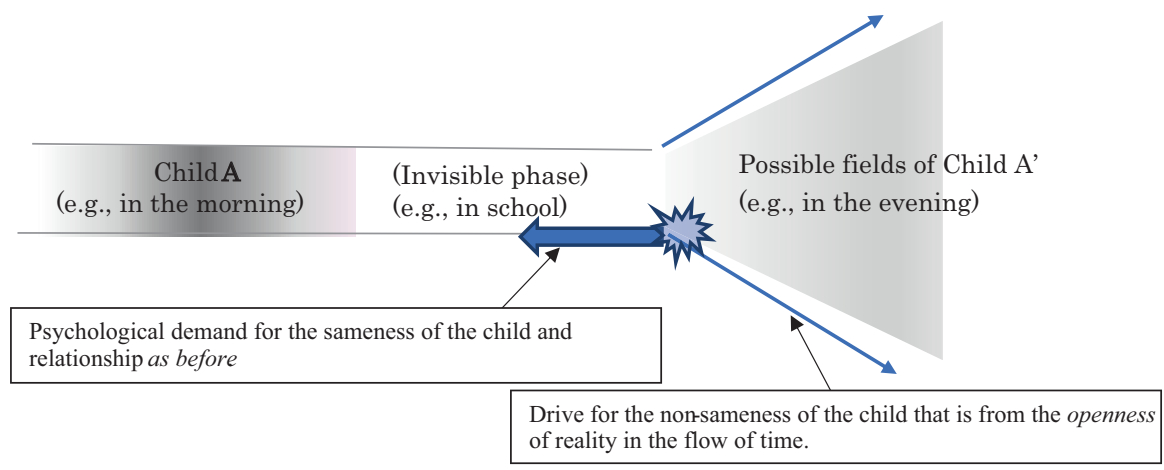

Irreversible time

Fig. 6.4 Model of a child's daily movement and the tension of same $<>$ non-same 
3 Mo: In the dance by the rabbits? The bat? (1 s) [Does he appear in] Another dance?

4 Mi: After the bats, (uh hum) then maybe rabbits, (hmm) bunny rabbits.

5 Mo: Mimi, the bunny ... Oops [I guess I was] wrong, snow rabbits!

6 Mi: Mina, the snow rabbit xx [inaudible].

7 Mo: Mina is [You are] a moon rabbit, aren't you? (Oh, [you are] right) A yellow rabbit, aren't you?

8 Mi: [I'm] Not a snow rabbit. (1 s) xx [inaudible]?

9 Mo: A flower rabbit. (Wrong) Mina, the moon rabbit.

10 Mi: That's right. Sayuri [Mina's friend, girl] and Sada Miki [Mina's friend, girl] play flower rabbits, don't they? (yes) Iiyama Mina and Sanae [Mina's friend, girl] are, well, moon rabbits, two moon rabbits and (yes) the white rabbit is, well, Tano (1 s) Tanokura (yes) Tano ... Tanokura, yeah, Tanokura Nagisa [Mina's friend, girl].

11 Mo: Tanokura Nagisa.

12 Mi: And then, Matsuzaka Aika [Mina's friend, girl] (yes) Machida Mina, [Mina's friend, girl] (yes) [you] see?

13 Mo: Yes, [I] see.

14 Mi: Three girls do that together, right?

15 Mo: Yes, but Mina [you] play in two, don't you?

In this episode, the participants mentioned are the same members whom Mina meets every day in hoikuen. Referring to these regular members serves to construct the sameness of the child's experience, but their animal roles in their performance, which derive from the children's mundane environment, add to their non-sameness in comparison with the same children the previous day. In this fashion, they are regulating same $<>$ non-same tension through this dialogical process. The relationship between the child and her mother is also implicated in this tension. In concrete terms, the child returns to her mother as one who needs her mother's help to show her the correct experiences; yet, in the latter half of the excerpt, she also attempts to assume a position to teach her mother experiences. This change of her position is not a very rale one in the longitudinal recordings, but can be interpreted as a non-same aspect of their relationship, in contrast with the relationship they regularly construct. In this way, the episode shows that the process in which we find the child's presentational self as a Gestalt quality achieves the regulation of same $<>$ non-same tension.

As Fig. 6.4 describes, the way this tension is regulated is not fixed to a single solution, but is instead open to a variety of possibilities. For example, it is also possible to suspend this regulation momentarily by throwing in a phrase such as, "I don't know" or "Nothing special, Mom." Actually, the child who wrote the story in Excerpt 5.4 insisted that she had nothing to write to her teacher. Identifying that there is nothing to tell or write is a simple, declarative construction of sameness despite the reality that involves some non-sameness. From the perspective of psychological approaches that stress the reproducibility of events, natural conversation is thus unpredictable and does not fit within the framework, just as many experi- 
mental music pieces do not for us. However, our focus on the tensions at work in the reunion can explain the nature of such whimsical interactions and meaning construction.

\section{Conclusion and Further Questions: Our Lives (and Our Research) Do Not Proceed like a Beautiful Music}

Beginning from a question concerning the occasional emergence of the clearer presentational self in mother-child conversations and the fluctuations of children's writings, this chapter has focused on the concept of reunion and two types of dialectic tension closely related to it as what brings about and promotes the dialogical work of meaning construction. In children's environments that hold the potential for meaning construction, reunion exists both as a result of the unavoidable divisions of our lives and as a deliberate event to be consumed. As I have discussed, citing some theoretical frameworks, researchers of psychology have also discussed what occurs in reunion with someone or something to understand our minds.

These ubiquitous but crucial events in our lives have the potential to restructure our framework for understanding the process of meaning construction in conversation or writings. The function of our meaning construction in dialogical processes-i.e., the foundation of presentational self - is the regulation of the continuing tension of same $<>$ non-same that derives from the tension of visible $<>$ invisible. Although we are predisposed to expect smooth reunions, the kind we enjoy when we listen to music, our lives also involve a variety of coincidences and the tension of same $<>$ non-same is resolved in various ways, as the attempts of Cage suggested to us. Researchers of psychology often suggest that our conduct stems from internal drives that make us move in a certain way. However, what we need to understand is the nature of tensions, same $<>$ non-same and visible $<>$ invisible, which are always in motion in the repeated reunion.

Dialogical meaning construction in storytelling works in these tensions and movements in combination with a variety of factors that appear coincidentally in our lives. For example, children's outward appearance provides a very strong foundation of their sameness in reunion, but it can also demonstrate their nonsameness (e.g., dirty shirts in the evening, different from cleanness in the morning). Children also retain their moods from the activities they experienced, which also work at the point that determines the talk $<>$ not talk bifurcation, because it is a possible option to opt out temporarily from active meaning construction. It's significant that all these factors work toward the regulation of tensions and are not factors that disturb the purposeful activity of conversation or writing. With this understanding, it is difficult to predict exactly when and in what condition meaning construction occurs.

The history of music also tells us that, if we adopt a framework that considers meaning construction as what works on the basis of such tensions and coincidence, 
my exploration is accompanied by a problem concerning its understandability. In the world in which people, including researchers, are eager to understand self and others by uncovering their dispositions or simple rules that predict our acts, a discussion concerning the emergence of a clearer presentational self based on the accidental occurrence of meaning construction is hard to understand, or is even irritating. This is like when a piece of experimental music is considered too abstruse, or when a sudden expedient transformation of identity in a fairy tale is regarded as unreasonable. Thus, another question for us is how to correctly include the richness of a non-stable world - the kind we find in conversational interactions-into our theoretical thinking without this being rejected as a bizarre and meaningless discussion only enthusiasts could appreciate. In the following chapters, I will discuss this issue by elaborating two dialectic tensions introduced here, with a focus on their roles in the process of development across a variety of aspects.

Open Access This chapter is licensed under the terms of the Creative Commons Attribution 4.0 International License (http://creativecommons.org/licenses/by/4.0/), which permits use, sharing, adaptation, distribution and reproduction in any medium or format, as long as you give appropriate credit to the original author(s) and the source, provide a link to the Creative Commons license and indicate if changes were made.

The images or other third party material in this chapter are included in the chapter's Creative Commons license, unless indicated otherwise in a credit line to the material. If material is not included in the chapter's Creative Commons license and your intended use is not permitted by statutory regulation or exceeds the permitted use, you will need to obtain permission directly from the copyright holder.

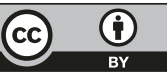

